\title{
The Limits of Modal KNOWLEDGE
}

\author{
REHAN P. VISSER \\ Independent scholar, SOUTH AFRICA \\ philovisser@protonmail.com
}

\begin{abstract}
In this essay I defend a nuanced but wide-reaching version of modal scepticism. I argue that claims about unrealised possibilities (part of an area that I term 'merely metaphysical modality'), unless logically (or analytically) impossible, are not justified by our intuitions, nor are they justified by any other means proposed by philosophers. I further suggest that it is likely that we have epistemic access only to this reality, the 'actual world'. It follows that, while we have modal knowledge pertaining to actualities (i.e., what has been realised) and impossibilities (i.e., what cannot be realised), we lack merely metaphysical modal knowledge (i.e., what has not been realised and is not ruled out by the prescripts of logic).
\end{abstract}

Keywords: Metaphysical modality $\bullet$ modal epistemology $\bullet$ modal scepticism $\bullet$ unrealised possibilities

Could the table at which I am writing this essay have been in a different position - not just at some other point in time, but right now? To ask this question is to ask whether things could have turned out differently, whether the history of the cosmos could have been otherwise. Many people claim to have at least some knowledge of (merely) metaphysical modality. Even Peter van Inwagen, a self-labelled 'modal sceptic', assumes that he is right in holding certain 'basic' modal beliefs (e.g., that the table could have been in a different position). In this essay, I defend a particular version of modal scepticism; specifically, I endorse the view that we lack knowledge of a category of merely metaphysical modality that I refer to as 'unrealised possibility'. ${ }^{1}$ In other words, neither those who hold that the table could have been in a different position, nor those who claim that it could not (i.e., that the table is necessarily in its position), are justified in making their assertions.

In Section I, I sketch a brief taxonomy of metaphysical modality. ${ }^{2}$ Section II is where I argue that we have no faculty of 'modalising'; all we possess are modal intuitions. I then discuss the problem of these intuitions for modal epistemology. Because our intuitions clash, we need an independent method to ascertain the truth of modal claims. In Section III, I present an inductive argument for modal scepticism by showing that none of the independent methods suggested by philosophers will do - not intuition; not perception; neither imaginability nor conceivability; not essentialism; 
and not possible-world theories. I give another reason to be sceptical of claims about modality in Section IV, namely, that it is doubtful that we have epistemic access to any alternative reality. Finally, in Section IV, I briefly gesture at some ramifications of this version of modal scepticism, explaining why I do not think they pose any problems and why this strand of modal scepticism is not unpalatable.

\section{I}

Before I jump into my arguments, I want to sketch a taxonomy of modality in order to clarify my use of several key terms. Under one viable conceptual scheme that I embrace here, modality comes in two flavours:

- Actuality: All actual things, by dint of being actual, are possible. We can call actual things realised possibilities. It is possible for black swans to exist because black swans actually exist - the possibility has been 'realised' in the actual world. Regarding epistemology, I affirm that we can have modal knowledge of realised possibilities insofar as we grasp actualities; that is, we can know that realised possibilities are indeed possibilities.

- Non-actuality:

- Logical impossibility: That which is logically (or analytically) impossible is a fortiori metaphysically impossible. A round square is conceptually incoherent, and so metaphysically impossible - it could never exist. Epistemically speaking, we can infer metaphysical impossibilities from logical impossibilities, but not vice versa.

- Merely metaphysical modality: The bone of contention - this is the category that I address in this essay. It contains all things that are neither actual nor violate the prescripts of logic, but are either merely metaphysically possible or impossible. The range of options are: (1) all things in this class are possible; (2) all are impossible; (3) some are possible and some are impossible. These are things, like unicorns, that I shall call unrealised possibilities. (Logical impossibilities are, strictly speaking, unrealisable possibilities, though that phraseology, while correct, can confuse. I will use 'unrealised possibility' as shorthand for an unrealised possibility that is not simultaneously unrealisable.) My thesis here is that we do not have knowledge of unrealised possibilities; that is, we do not know whether an unrealised possibility constitutes a metaphysical impossibility or a non-actual metaphysical possibility (see the figure below). 


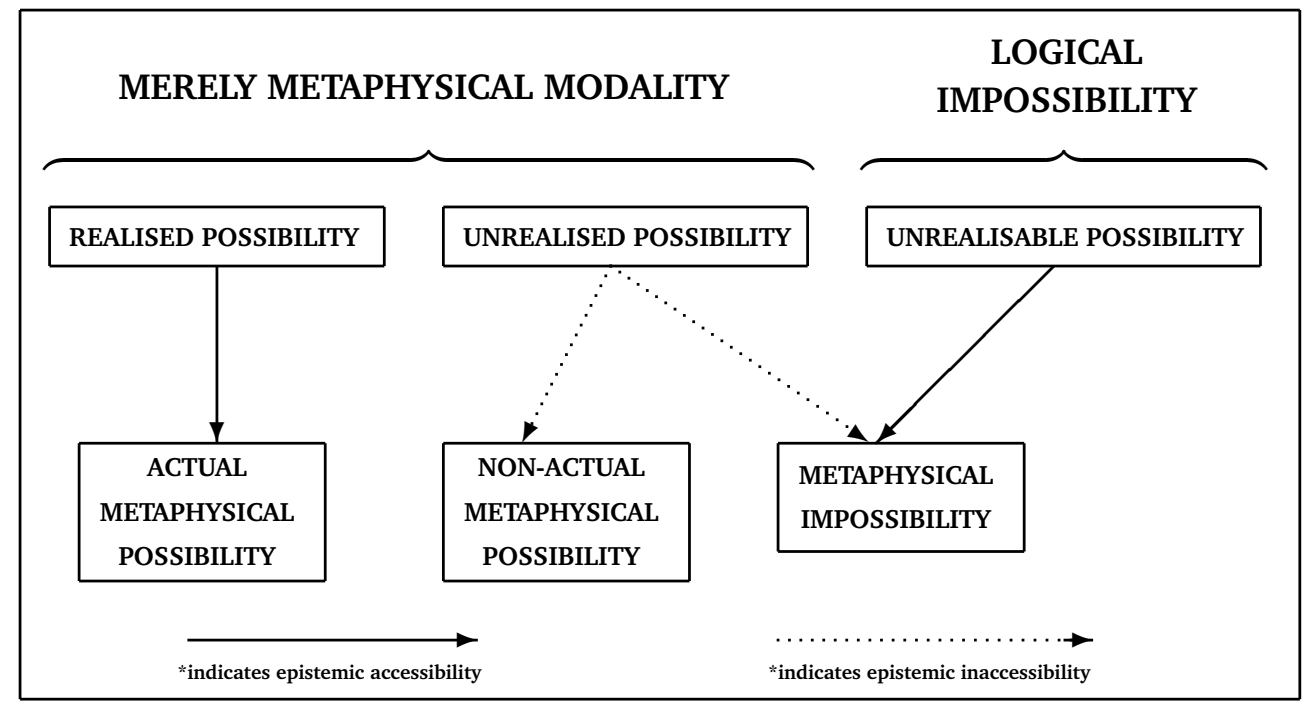

Many metaphysicians assume that at least some claims about unrealised possibilities are justified. In other words, they assume that we can know in which of the two categories some unrealised possibility claims belong: non-actual metaphysical possibility or metaphysical impossibility. In this essay, I argue that this assumption is baseless; we do not have this sort of modal knowledge. I now turn to the first of my sceptical arguments.

\section{II}

Van Inwagen argues that some modal facts are inaccessible to us. Judgements about modality, he says, are analogous to judgements about distance. In the past, many people looked up at the sun and the moon, and took them to be as far away as the most distant things on the horizon. People were thus grossly mistaken about the length of celestial distances until they applied reason to them. In much the same way, van Inwagen (1998, p.70) thinks that we can have some basic modal knowledge that we obtain non-inferentially, just as we come to know things via our intuitive sense of distance. Using reason, we can further our understanding of modality, just as astronomers learnt about the real distances between Earth and other celestial bodies when they started to employ reason (van Inwagen 1998, pp.69-70). Yet he thinks there are still many modal claims about which we cannot know the truth of the matter, such as the possibility of transparent iron (van Inwagen 1998, p.71). According to him, philosophers who think they can conceive of transparent iron "are fooling themselves" (van Inwagen 1998, p.71). He cites Richard Gale as an example of one such philosopher. Much like other philosophers, Gale is unable 
to discriminate those cases in which his modal judgments are products of his ordinary human powers of "modalization" from those that are based on his immersion in a certain philosophical environment - an environment composed of philosophers who unthinkingly make all sorts of fanciful modal judgments because they've always been surrounded by philosophers who unthinkingly make the same sorts of fanciful modal judgments. He is as unaware of his immersion in this environment as a fish is of its immersion in water. He is unaware that the modal beliefs he expresses or presupposes when he says, "We'd have had more room if we'd moved the table up against the wall", (e.g., that it was possible for the table to be up against the wall) and the modal beliefs he gives such confident expression to in his writings on philosophical theology have quite different sources. The former have their source in our ordinary human powers of "modalization" ... [while] the latter have their source in his professional socialization, in "what his peers will let him get away with saying". (van Inwagen 1998, p.73)

Note, firstly, that van Inwagen seems to think that the claim "[w]e'd have had more room if we'd moved the table up against the wall" incorporates the possibility "for the table to be up against the wall". This is key; I shall return to this assumption and show why it is problematic. But first I aim to show that the idea of our "ordinary human powers of "modalization"' is a mere chimaera.

Van Inwagen distinguishes between basic and specialised modal claims. His case for modal scepticism turns on this distinction. The example of the table constitutes a basic modal claim. In contrast, examples of specialised modal claims that he provides are: "It is possible for there to be a perfect being"; "It is possible that I exist and nothing material exist[s]"; and "It is possible that there exist vast amounts of suffering for which there is no explanation" (van Inwagen 1998, pp.67-8). These are the sorts of things, van Inwagen ironically asserts, which are only thought to be knowable because of Gale's "professional socialization" (i.e., academic philosophy), but which are, in fact, unknowable.

I say 'ironically' because van Inwagen seems to be wholly unaware that his argument against specialised modal knowledge applies equally to the notion of basic modal knowledge. It is, I think, revealing that he offers no distinguishing factor between basic modal knowledge and specialised modal knowledge. I suspect that the reason he does not offer such a distinction is because no non-arbitrary distinction exists. Where is the boundary between things we can grasp with our ostensible power of 'modalising' - whatever that is; van Inwagen does not elaborate on its nature and things that are out of its reach? Van Inwagen is mute on this crucial point. This is problematic, because a distinction must exist if it is to explain why we can have knowledge of basic modal propositions but not of specialised modal propositions. Moreover, van Inwagen, as far as I can tell, has not provided a rigorous argument for how we can know only the former (as opposed to the latter). I take up the baton he 
has held up by providing a defence of the view that we do not have modal knowledge of a particular kind, namely, knowledge of unrealised possibilities.

Strikingly, as van Inwagen brazenly admits, he has no way of justifying basic modal statements. He rejects the possibility that we can know by virtue of crafting and investigating a counterfactual scenario where the table is in a different position. This cannot explain how we know that the table could have been elsewhere, he says, because we do not know whether the scenario itself might be impossible. We can only know if something is possible if we know that the counterfactual scenario in which it occurs is possible. Furthermore, van Inwagen continues, even if we know that a counterfactual scenario is possible, it seems that we can only know how the scenario confers possibility if we know how the scenario itself is possible. Still, van Inwagen (1998, pp.75-6) takes it that we just know that the table could have been in a position other than the one it is presently in. The fact that such knowledge is mysterious is not a problem for him; van Inwagen (1998, p.76) believes that we do not require an account of how we come to know these modal propositions. Perhaps he is worried that such a requirement for justifying our modal claims is too strong, as it would result in an infinite regress, in much the same way that the KK principle is supposed to. ${ }^{3}$

At any rate, whatever his motivation, I suspect that van Inwagen is likely as much a victim of his intellectual environment as Gale is. For it surely is a problem - absent any account of how we can come to know even ordinary modal propositions, we have no good reason to believe that we have modal knowledge. Moreover, if, as van Inwagen contends, there is no way of accessing specialised modal knowledge, and there is no distinction between specialised and basic modal knowledge, it seems to follow that we have no way of accessing basic modal knowledge either. Much like specialised modal claims, we cannot access the truth of, say, whether the table could have been in a different position. This, I argue, despite what many metaphysicians assume, is right: the truth of modal claims are blocked by an epistemic barrier. So, how does van Inwagen know that the table could have been elsewhere? The implications of his own argument is that he does not; it is only because of van Inwagen's professional socialisation — "what his peers will let him get away with saying" — that he stubbornly thinks he knows that the table could have been in a different position. ${ }^{4}$

Let me elaborate a little. Van Inwagen (1998, p.73) declares that he can "'modalize' like normal people". But what is this "ordinary human power" of modalising that he speaks of? One might think that this ability to modalise could parallel how senseperception provides us with knowledge: I see a hand in front of me; hence, I know there is a hand in front of me. Presumably, I imagine or conceive of a scenario ${ }^{5}$ such that the table is in a different position, and I thereby come to know that the table could have been in a different position.

Unfortunately, this example is disanalogous to perceptual forms of knowledge in 
a critical respect. When I see my hand, I have evidence for the claim "I know there is a hand here", and I have a rough causal story to tell. What counts as evidence in the modalising example? What does my imagining or conceiving of a scenario have to do with the way world could have been? As Quentin Smith rightly notes, taking imaginability or conceivability to have any relevance to the way the world could have been opens one up to charges of psychologism and speciesism. The former worry is that "psychological properties are not identical with [n]or logically equivalent to assertions about metaphysical modalities" (Smith 2001, pp.33-4), while the latter asks: "Why should what is metaphysically possible, impossible or necessary be determined by what can or cannot be conceived or imagined by the species or organisms to which we belong"? (Smith 2001, p.34) ${ }^{6}$ Instead of special modalising powers, then, all van Inwagen and his ilk have are modal intuitions.

To see why this is a problem for modal epistemology, consider that people's modal intuitions can conflict; some think that the table could have been in another position, but others believe it could not have been elsewhere. Baruch Spinoza and Diodorus Cronus were two famous necessitarians - people who hold that there is only one way the world could have been; nothing could have been otherwise. The problem with clashing intuitions is that we need an independent standard to assess which intuitions are correct. ${ }^{7}$ Without such a standard, we are in no position to determine which intuitions should be accepted and which rejected. Consider the parallel with moral dilemmas. If someone thinks that suicide is never morally acceptable, but someone else thinks that it is at least sometimes morally acceptable, then we need some way of establishing which view to accept. To do that, we require an independent moral standard. ${ }^{8}$ The same goes for modality. Since we lack an independent standard in the case of clashing modal intuitions, and barring another method for ascertaining the veracity of modal claims, which in the next section I argue has not been identified, the epistemically responsible position is to admit that we do not have modal knowledge of the type claimed by van Inwagen et al. If someone asks whether the table could have been in a different position, our reply should be that we do not know. That is to say, we ought to be modal sceptics.

Robert Nozick also argues that we lack a faculty for making accurate modal judgements. His strand of scepticism differs from my own, however, in that he concludes that there are no metaphysical necessities. Nozick is sceptical of the idea that evolutionary processes endowed us with a faculty for making accurate judgements about what is or is not possible. He reasons: "Since our ancestors evolved in the actual world, there were no selective pressures to reward accuracy about all possible worlds, and there was no handicap to being right only about the actual world" (Nozick 2001, p.122). Thus, our modal intuitions are unable to gives us the truth of our necessity claims (Nozick 2001, pp.124-5). As I have argued, this last statement is right, but Nozick draws the wrong conclusion from it. Rather than showing that nothing is 
necessary, the inability to modalise means that our beliefs about unrealised possibilities, which are either real possibilities or impossibilities (negative necessities), are unjustified. This includes the view that there are no necessities. If we cannot have knowledge regarding what must be the case or what could have been different, then it makes no sense to say that everything is contingent. Rather, what it means is that we should be sceptical of such claims. At any rate, modal scepticism does not need an evolutionary argument; in Section III, I show how the various efforts to justify modal claims all fail.

Before I do so, I want to quickly address a concern that some may have. There is a suggestion that some intuitions are more theoretically virtuous or valuable than others. Were we to weigh the costs and benefits of various intuitions against one another, might it not turn out than the necessitarian's intuitions, when compared with van Inwagen et al.'s, are worth less (or vice versa)?" "Well," one might ask, "what kind of theory could we employ, and how would we rank the intuitions?" Note that any idea of privileging the view that basic modal knowledge is accessible to us is out of the question, because whether it (or any other merely metaphysical modal knowledge) is accessible to us is precisely the matter at hand! In other words, we cannot favour the intuition that the table could have been in a different place simply to preserve the idea that we can have knowledge of unrealised possibilities. If there are reasons to think that some modal intuitions are more reliable or otherwise expedient, then I challenge the reader to find them. Suffice it to say, I am pessimistic about the success of locating an intuition that directs us to knowledge of an unrealised possibility.

\section{III}

Consider the example of a table being in a place different to the one that it actually occupies at a given point in time. There is a fact, $P$, about actuality: the table $S$ is in location $L$ at time $t$. I obtain knowledge of this realised possibility by using my perceptual apparatus: I see $S$ in $L$ at $t .{ }^{10}$ Now compare $P$ with the unrealised possibility $P^{*}$ such that $S$ could have been in $L^{*}$ (a location different to $L$ ) at $t$. Knowing $P$, I come to believe, as many metaphysicians do, that $P^{*}$; that is, I think that $S$ could have been in $L^{*}$ at $t$. The question is: what justifies the move from $P$ to $P^{*}$ ? More generally, we may ask: can we have knowledge of modality? ${ }^{11}$

I have stated that we do not have a faculty or mechanism by which to justify our modal beliefs. But there is a myriad of potential candidates that metaphysicians have offered as just such a means. 


\section{Perception}

To start with, it should be noted that it obviously cannot be perception. Anyone who insists that I can see the table $S$ in location $L^{*}$ at time $t$, and that by seeing something in a given location and at a given time I can come to know that it could have been there, is equivocating on the word 'see'. ${ }^{12}$ I plainly do not see $S$ in $L^{*}$ at $t$, other than in my 'mind's eye', for it is not there in $L^{*}$ for me to see - after all, $S$ is in $L$. So, I cannot come to know the unrealised possibility $P^{*}$ via perception.

\section{Intuition}

Intuiting that $S$ could have been in $L^{*}$ at $t$ does not help either because, as I argued earlier, clashing intuitions require some kind of independent method of determining which intuition to accept. Say Spinoza, or some other necessitarian, intuits that $S$ could not have been in $L^{*}$ at $t$; that is, they intuit that not- $P^{*}$. In contrast, van Inwagen intuits that $P^{*}$. Trying to obtain knowledge of the unrealised possibility of whether or not $S$ could have been in $L^{*}$ at t will quickly devolve into a shouting match of little import. Neither side can definitively say who is right. It therefore would be wrong for van Inwagen to conclude that he can come to know, through his 'modalising' faculty (intuition), the truth of $P^{*}$. In any event, what is required of him is to know that the world could have turned out differently. How could the table have come to be somewhere other than where it is? Perhaps someone put it there. But then this person must have been in different locations leading up to that moment of moving the table and not the ones they were actually in. And this must be accounted for, and whatever accounts for that must be accounted for, and so on back into a wholly alternative history of the cosmos. There is no way that an intuition, regardless of whether it clashes with other intuitions, can confer knowledge to the effect that the entire history of the cosmos could have been different. ${ }^{13}$ I return to this important observation, one that van Inwagen also makes, in Section IV.

\section{Imaginability and Conceivability}

Imaginability and conceivability are two other capacities that are said to provide justification of our modal beliefs. Several metaphysicians, such as David Chalmers (2002) and Stephen Yablo (1993), have adopted the C-P thesis: the idea that whatever is conceivable is possible. However, Alex Byrne (2007) has argued persuasively that neither imaginability nor conceivability can lead us to truths about possibility. The three kinds of imagination that Byrne examines are: perception as an analogy to imagination; sensuous imagination; and positive conceivability. On the perceptual analogy, "imagining stands to [unrealised] possibility as perceiving stands to actuality" (Byrne 2007, p.132). One point that tells against this analogy is the point I 
mentioned earlier about perceptual data counting as evidence for knowledge. The disanalogy in the epistemological context is that there is no clear reason why simply imagining something should count as evidence for unrealised possibilities. As Byrne emphasises, there is a causal process involved in perception, whereas no such causal process can be found in imagination. Light reflects off a sunflower into my eye, from which the information is fed to my brain, enabling me to perceive yellow petals. There is, however, no analogous causal process involved when I imagine merely possible pink sunflower petals. Put another way, merely possible things have no actual effects in this world and thus imagining them cannot be a source of modal knowledge. My imagining pink sunflower petals thus has no bearing on whether they can exist (Byrne 2007, p.133).

So, for the analogy to be edifying at all, imagination must involve appearances, just as perception does. And if I can be mistaken about what I apparently perceive, then I can be mistaken about what I apparently imagine, too. Byrne thinks that there are modal illusions of this sort (2007, p.133). Imagine a polar bear dyed purple. This kind of imagining has some propositional content - perhaps 'purple polar bears exist'. But imagining that purple polar bears exist is not the same as imagining that purple polar bears could have existed. Modality is concerned with the latter. In this respect, imagination is too much like perception. The propositional content of perception is 'white polar bears exist', not 'white polar bears could have existed'. As Byrne elucidates, the problem is as follows:

If sensuous imagination stands to possible worlds as perception stands to the actual world, then the content of sensuous imagination should concern possibility, not actuality. Then, just as perception involves the appearance of actuality, sensuous imagination would involve the appearance of possibility. But that's not right: if sensuous imagination involves the appearance of anything, it's the appearance of actuality, not possibility. What "appears to be so", when one imagines a purple polar bear, is that purple polar bears exist, not (merely) that they could have existed (Byrne 2007, p.134).

In other words, the problem is that our imagination cannot inform us about (unrealised) possibility in a way that is relevantly similar to the way that our perception informs us about actuality. Byrne takes this problem to affect sensuous imagination and positive conceivability equally. He thus concludes that the analogy of perception is best rejected (Byrne 2007, p.134).

Despite not being a faculty for 'perceiving' the truth about modal statements, one might still wonder if sensuous imagination can somehow guide us to knowledge of unrealised possibility. Byrne investigates visualisation, which he considers a special type of sensuous imagination. ${ }^{14}$ The similarity between visualising and seeing is one of content: a mental representation of something 'visual' contains some information such that seeing and visualising a tiger both involve something that 'looks' like a tiger. 
The problem with thinking that sensuous imagination can inform us about what is possible, argues Byrne, is that we can visualise certain impossibilities. Of course, if we can visualise impossibilities, then sensuous imagination cannot be a guide to unrealised possibility (Byrne 2007, pp.135-6).

The problem with the examples that Byrne gives is that he assumes what counts as an impossibility. This may be acceptable for his project, but for my purposes here it needs to be the case that we can sensuously imagine logical impossibilities for his argument to work, since I maintain that these are the only metaphysical impossibilities that we can know about. But it does seem that we can do this. As Smith (2001, p.33) points out, a ghost is a thing "that is both embodied and disembodied, which is a logical contradiction". Yet I can visualise a ghost as a kind of ethereal entity, which can pass through some solid objects but cannot pass through others. Or, if this is not accepted, I can imagine that Hesperus and Phosphorus could have been different celestial objects, as ancient people believed them to be. Yet Hesperus is identical to Phosphorus, and identities are necessary; it is logically impossible for $P$ not to be identical to $P .{ }^{15}$ We can sensuously imagine impossibilities, and so Byrne's argument stands: sensuous imagination is not a guide to unrealised possibility.

Does positive conceivability fare any better? Byrne (2007, p.138) argues that it does not - the reason being that positive conceivability is "one and the same as" sensuous imagination. To positively conceive of a thing is, in Chalmers's (2001, p.150) words, to "imagine a specific configuration of objects and properties". Although Chalmers (2001, p.151) thinks that sensuous imagining is merely a subset of positive conceiving, as other types of positive conceiving are not "grounded in imagery", Byrne thinks that all kinds of positive conceiving can be construed in terms of visual representations. For instance, one can imagine Germany winning World War II - an example Chalmers takes to be of positive conceiving but not of sensuous imagining - by visualising Hitler waving from a Buckingham Palace balcony. The difference between sensuous imagining and positive conceiving is thus not one of kind but one of degree (Byrne 2001, pp.137-8). And because sensuous imagining is an inadequate guide to unrealised possibility, it means that imaginability and conceivability are unhelpful in giving us such modal knowledge. ${ }^{16}$

One worry for Byrne, however, is that he has not definitively shown that all positive conceiving collapses into sensuous imagining, something he needs to do in order for his argument to go through. Can all positive conceiving be reduced to sensuous imagining? I am not sure that it can, but it does not matter, since I can level the same criticism against positive conceiving that Byrne levels against sensuous imagining. That is to say, we can positively conceive of impossibilities - we can conceive of the existence of ghosts without having to visualise or otherwise sensuously imagine them ${ }^{17}$ - and, as such, positive conceiving is an unhelpful guide to unrealised possibility. 
In any case, it is not clear why we should think that our ability to conceive of or imagine a counterfactual scenario justifies a belief that such a scenario could have occurred, especially if we consider the two powerful objections against the modal powers of imaginability and conceivability mentioned earlier, namely, Smith's objections from speciesism and psychologism. It should be clear, therefore, that neither imagining nor conceiving, irrespective of how they are fleshed out, can give us knowledge of unrealised possibilities.

\section{Essentialist Theories}

Another option touted by some metaphysicians is to deductively infer modality from an object's essence. E. J. Lowe's (2012) argument for this move can be laid out as follows:

P1. $E$ is an essential property of $x$.

P2. $H$ is incompatible with $E$.

P3. If $E$ is an essential property of $x$ and $H$ is incompatible with $E$, then $x$ cannot be $H$ (i.e., it is impossible for $x$ to be $H$ ).

C. Therefore, $x$ cannot be $H$ (i.e., it is impossible for $x$ to be $H$ ). ${ }^{18}$

Let us use an example to see how this is supposed to work. It is the essence of a square that it has four sides equal in length. Another property — say, having only three sides - is incompatible with having four sides. So, if it is essential to a square (what Lowe also calls its 'real definition') that it has four sides, and if having four sides is incompatible with having (only) three sides - both propositions that are beyond doubt - then it is impossible for a square to have (only) three sides. Voilà! We can infer modalities from the essences of things.

Notice, however, what kind of example we used to illustrate the method's success. The example of the square's sides works because it is completely impossible for a square to have simultaneously four and (only) three sides. As I have stated, I believe that we can infer metaphysical impossibilities from conceptual impossibilities; indeed, Lowe's argument structure is exactly the one I would use to do so. But it is a method with limitations, as it does not extend to things outside the realm of logical impossibility. In fact, the reason for the above example's success is because what we mean when we say that two properties are incompatible (or, more strictly, what must be meant for the argument to work) is that it is logically impossible for them to be compossible. ${ }^{19}$ The argument only shows that a logical impossibility implies a metaphysical impossibility. What such an argument cannot provide, however, is knowledge of unrealised possibilities.

Why not? Well, two properties are either compatible or they are incompatible; either they are compossible or they are not. As I have just argued, we can have 
knowledge of impossibilities when we know that two properties are incompatible, precisely because it is logically (conceptually) impossible for them to be compossible. What about two properties that are compatible (i.e., where it is not logically impossible for them to be compossible)? Can we know that compatible properties are possible, that the cosmos could have turned out in such a way that they coexisted, even though they do not actually coexist in a particular object?

The problem here is an(other) asymmetry of epistemic accessibility: we can derive knowledge of metaphysical impossibilities from logical impossibilities, but we cannot make a similar move for metaphysical possibilities. This is because the concept of a 'logical possibility' is epistemically useless (van Inwagen 1998, p.71). For instance, it is logically possible that someone will never break the two-hour mark for running a marathon; ${ }^{20}$ equally, it is logically possible for someone to run a marathon in under an hour. Neither option is precluded by the prescripts of logic (nor the coherence of the concept). How, then, are we supposed to infer modal truths? The fact that no logical rules would be broken in a 'logically possible' scenario does not give us any idea about the metaphysical possibility or impossibility of someone running a subtwo hour marathon. Deducing modal truths from essences will therefore not work for the kind of knowledge that we are after, namely, knowledge of unrealised possibilities (unrealisable possibilities being the exception).

\section{Possible Worlds}

Before I conclude that we cannot obtain modal knowledge, there is one last candidate for the source of justification of this kind of knowledge to assess. The idea is that we can craft a theory of possible worlds and, from the similarities between our world (i.e., the actual world) and other possible worlds 'close' to ours, we can infer what is possible at the actual world. We can thus move from knowledge of a relevantly similar object's realised possibility at another world to knowledge of an object's unrealised possibility at our world. Alternatively, one might think that $P$ is possible but unrealised when $P$ is true at some possible world; $P$ is necessary when $P$ is true at all possible worlds; and $P$ is impossible when $P$ is true at no possible worlds.

There are numerous problems with this reified notion of possible worlds. Possibleworld theorists tell us that possible worlds do not interact with or influence our actual world at all. But if they exist separately from our world, whether on some other 'plane' or as abstract objects, then what bearing can they have on how actual things at our world could have been different? In addition, if these possible worlds are real but completely separate from the actual world, then how can we know what they are truly like? Another way of asking this question is to ask how we can come to know the truth or falsity of a proposition $P$ at a given possible but non-actual world. Are we not using our faculty of imagination to 'access' these possible worlds in order to 
establish the truth-value of $P$ ? I cannot think what other cognitive faculty we can utilise that will shed light on these mysterious possible worlds. Thus, I take there to be prima facie reason for thinking that knowledge of possible world content does not confer knowledge of modality because, as I argued earlier, imaginability cannot be the source of modal knowledge. ${ }^{21}$

David Armstrong's (1989) combinatorial approach, whereby possible worlds are conceptualised as rearrangements of existing elements of the actual world, is also no use here, because, to revise van Inwagen's point, we would have to know that a possible world really does exist before we could use it to infer what is possible at our world. Yet how can we do this when the existence of possible worlds depends on an intuition? The author of the Stanford Encyclopedia of Philosophy entry on 'Possible Worlds' unwittingly alludes to this problem when he states that "[i]ntuitively ... the actual world of which [our] immediate situation is a part is only one among many possible worlds" (Menzel 2017). I have already laid bare the various problems with such intuitions. Jonathan Bennett (2000, p.164) puts it more forcefully: "modal intuitions are not a basis for our modal opinions; they are our modal opinions, so that the epistemic 'theory' which takes them as our basis is empty [and] is not a theory at all". The very notion of 'possible worlds' therefore appears to be unhelpful for the purpose of justifying modal statements, because to assume the existence of possible worlds just pushes the problem of justifying modal claims one step back. ${ }^{22}$

Is this too hasty? Otávio Bueno and Scott Shalkowski argue that we do not need to use any kind of imagination to know that, for example, an African elephant would have broken Ernest Hemingway's table if it had sat on it. On their account of possibleworld theory, "we know that [the table] would have broken simply by knowing the properties that such an elephant has and the properties the table has" (Bueno and Shalkowski 2014, p.680). It is very interesting to note what is being posited here, and what we can legitimately infer from it. The hypothetical scenario takes the form of a counterfactual conditional: if an elephant had sat on Hemingway's table, then the table would have broken. Bueno and Shalkowski believe that we can acquire modal knowledge thusly.

But what is the relevant modal question here? There is a difference between knowing that the table would have broken, had the elephant sat on it, and knowing that the table genuinely could have been broken in this way. Only the latter is a claim of the relevant sort (i.e., a merely metaphysical modal claim). The former, on the other hand, is a matter of inferring the truth-value of a consequent from a false antecedent. Modal knowledge of this kind, I agree, does not appear to be beyond us. Hemingway's table, assuming it was not very large, would surely not have withstood the mass of an African elephant sitting on it. ${ }^{23}$

By contrast, determining whether the antecedent or the consequent is metaphysically possible is an altogether separate enterprise, and these are not things that we 
can simply infer from knowing an object's properties. We can see this again by revisiting a quote from van Inwagen. He seems to think that the statement "[w]e'd have had more room if we'd moved the table up against the wall" means "that it was possible for the table to be up against the wall". But these are not equivalent! Again, it seems plausible to suggest that we can know that, had the table been moved up against the wall, then (ceteris paribus) we would have had more room. Yet nothing about this allows us to infer that we actually could have changed the course of history or the trajectory of the universe by moving the table up against the wall (at that moment in time). As van Inwagen himself notes, in order to know that something in a counterfactual scenario is possible, in this case the antecedent, we must first know that the scenario itself is possible. But we do not know that this scenario could have happened - the question of moving the table is exactly what is assumed! So, Bueno and Shalkowski's possible-world theory does not provide us with the requisite modal knowledge; it may tell us what would have happened, had a particular set of counterfactual events arisen, but this does not tell us that such a set of counterfactual events really is a genuine metaphysical possibility.

Having established that none of the proposed means for verifying merely metaphysical modal claims is feasible, I can only point in the direction of modal scepticism. For while this inductive argument does not prove the veracity of the sceptic's thesis, it surely counts in their favour. Given the difficulty of establishing a means of justifying claims about unrealised possibilities, I believe that modal scepticism is the epistemically responsible position to adopt. In the next section, though, I take the thesis of modal scepticism a step further by giving it an even stouter defence.

\section{IV}

What would it take for us to have modal knowledge of the sort we are after here? To know whether the table could have been in another place would require us to know that cosmic history could have been different. This, I suggest, is likely out of our reach. Here is why. Knowing whether the history of the cosmos could (or could not) have been different involves knowing the actualising principle, that which determines being or non-being by converting the merely possible into the actual. But it is doubtful that we can know even whether there is such an actualising principle and thus whether the cosmic trajectory is static or dynamic. Hence, it is unlikely that we can have knowledge of unrealised possibilities.

How could one know that the cosmos could have been different to what it is, that reality itself might have been otherwise? Our problem is that we are confined to this reality (call it $R$ ); we do not have epistemic access to other realities. To know about another reality $-R^{*}$ - we would have to know that $R^{*}$ occurred; we would first have to be in that reality. But if $R^{*}$ occurred, then our reality $-R-$ would not occur, for 
only one reality can be reality. Now, if we (or our counterparts) were in an alternative reality like $R^{*}$, then we would have access only to said reality. Consequently, we would not know whether $R$, as an example, was genuinely possible or not. This is merely an extension of the point raised by van Inwagen, namely, that in order to know whether something is possible or impossible first requires us to know whether the situation that gives rise to it is possible.

How could we know that this other situation, this alternative reality, $R^{*}$, is itself possible? Possible-world theorists simply assume that it is - that is why they call it 'possible worlds'. Obviously, this will not do. Those who hold that there are possible but non-actual things (e.g., unicorns) and that we can know that at least some of them are metaphysically possible, must explain why such things have not been realised (i.e., they must account for the actualising principle). It would not be enough to say that the cosmos had to have unfolded differently. Indeed, that is what is at stake! What needs to be explained is why the cosmos unfolded the way it did and why it did not unfold differently so that (for example) unicorns were realised.

This last point is vital. There is something about the very concept of an unrealised possibility that is never realised that seems to suggest that it possesses a metaphysical (i.e., not logical) impossibility. After all, what else can account for the fact that it was not realised? What would it mean to be able to be - to be possible - but never to be? This is not to aver that unrealised possibilities that are never realised are somehow unrealisable; but it is to say that an account of the phenomenon where possible things are or are not realised - whether the actualising principle applies or not - must form part of modal epistemology. Note that giving an explanation to the effect that an unrealised possibility (unicorns) was not realised because it did not form part of the reality that was realised $(R)$ is simply restating the problem. As such, I do not believe that a satisfactory account of the desired modal knowledge can be given. Claims regarding unrealised possibilities can serve an informational role when abstracted into the realm of ideas, as I highlight in Section V; in the metaphysical realm, however, knowledge of them remains out of reach.

Again, I must reiterate that to say that things, as a matter of fact, could have been a certain way is not equivalent to saying that things would have been that way if some other set of prior conditions had transpired. ${ }^{24}$ To see why, let us revisit the elephant example. In the counterfactual scenario, "if the elephant sat on Hemingway's table, then the table would have broken", the 'elephant sitting on the table' forms the antecedent. Put another way, it is the assumption. Assuming that the elephant could have sat on the table does not imply that the elephant could have sat on the table. Does the fact that the elephant would have broken the table, if it had sat on it, mean that it could, as a genuine possibility, have sat on the table? To know that, we would have to know whether the elephant could have sat on it in the first place. But this is precisely the matter in question! 
Nor can we say, with this example, that knowing that the table would have broken if the elephant had sat on it is equivalent to, or will give us knowledge of, the fact that the table could have broken. For us to know that the table could have broken (when it did not) we would have to know that the elephant could have sat on it (or some other table-breaking reason). And so we are back to the assumption in the antecedent. So, when Timothy Williamson (2007, pp.152-3) purports to show that a counterfactual conditional is logically equivalent to possibility, the only kind of possibility he can have in mind is logical possibility. Following van Inwagen, I have already demonstrated that, not only is this concept not the same as merely metaphysical possibility, the notion of logical possibility is epistemically useless. Williamson's case for equating 'would' and 'could' claims is a non-starter.

\section{V}

Let me recap my position. Modal questions of the sort I have explored here are ultimately questions about the flexibility of reality. Questions about realised possibilities are questions about how the world is, whereas questions about unrealised possibilities are questions about how the world could have been different to what it is. We seem to have answers to questions of the former variety; such things are knowable. However, we do not have answers to questions of the latter variety, excluding cases of unrealisable things, even though many of us think we do. In fact, such things seem fundamentally unknowable, because we lack a means by which to access knowledge of this type. Even Williamson (2005, p.20), who rails against my kind of "extravagant skepticism", admits that it is "quite unlikely" that we possess a "special cognitive faculty" we use to access truths about metaphysical modality. This does not, however, mean that such knowledge is impossible, for, as I have argued, such a claim would be unjustified. (For one thing, it would render my position self-contradictory.) Perhaps the world could have developed in such a way that we did have access to knowledge about unrealised possibilities. Although it is difficult to see how this would work, we cannot rule it out. But our inability to have modal knowledge of the desired sort should come as no surprise, as our cognitive capacities are inadequate for the task. Moreover, there is nothing in the nature of realised possibilities that can tell us whether unrealised possibilities are genuinely possible or whether they are, in fact, impossible. It seems as though nothing short of a daemonic revelation can tell us whether the world might have turned out differently. Claims about the necessity or contingency of anything which is not also a claim about logical necessity or absolute impossibility, even those concerning the existence of the cosmos, are thus unjustified.

Having said that, two potentially very serious consequences of modal scepticism are immediately apparent. The first concern is that modal scepticism commits us to getting rid of counterfactual conditional knowledge, while the second worry asks 
what this view means for our ordinary modal discourse. Regarding the first potential consequence, one may think, as Williamson does, that scepticism about modal knowledge is too extreme, for it entails scepticism about counterfactual conditional knowledge. Without critiquing Williamson's account directly, I think this problem can be dodged by appealing to the crude distinction I made between 'could' knowledge and 'would' knowledge. This involves teasing apart knowledge of the genuine possibility or impossibility of the antecedent from what follows from the antecedent. As I suggested in Section III, it seems plausible to say that we can know that there would have been more space if we had moved the table up against the wall (i.e., the consequent) without being committed to saying that we thereby know that the table indeed could have been moved up against the wall (i.e., the antecedent), which is really the claim about unrealised possibility we are interested in. In other words, I am claiming that the truth of a consequent can be known irrespective of whether the antecedent expresses a metaphysical possibility or impossibility - perhaps not in all cases, but at least in some, such as the examples of the table being moved and the table being broken by an elephant. If this distinction is legitimate, then counterfactual conditional statements remain intact as a potential source for some kind of modal knowledge, and the thesis of modal scepticism (which speaks solely to claims about unrealised possibilities) is not threatened.

The second concern about modal scepticism is what the ramifications are for our ordinary modal discourse. Is the conception of the merely possible viable and/or valuable in any way? If we are to continue to employ our current notion of possibility, then one way of understanding it would be to reconfigure it as an epistemic notion instead (Erkenntnismöglichkeit). This is because we are not justified in making claims about what is or what is not metaphysically possible unless we know something to be actual or logically impossible. But, one might ask, if we are to do this, how can we explain the usage of our ordinary modal discourse and its influence on our behaviour? For example, cyclists wear helmets because there is a 'possibility' of their having an accident, whereas pedestrians on city streets do not wear helmets, even though there is a seemingly equivalent 'possibility' that a piano will fall out of a window above. How can epistemic notions of possibility account for this discrepancy in behaviour? Although I cannot sketch out a full answer here, I think this can be accounted for by pointing to: (1) our experience of the universe as being constant, in the sense that natural laws have always turned out to behave the same in the future as natural laws have behaved in the past, and our assumption that nature is uniform; (2) the fact that we reason probabilistically, drawing on background information relevant to activities that we engage in; and (3) the variations in individual human psychologies, which can cause different people to act upon the same information in disparate ways. In conjunction, these three explanations seem to be able to make sense of the fact that, for example, many cyclists wear helmets but pedestrians do not. 
I do not think that we should be scared of embracing modal scepticism. As philosophers, we ought to be more mindful of the boundaries of our capacities, and not to be afraid to admit to epistemic limitations. So, why have philosophers, who are so good at laying bare inconsistencies and gaps in our knowledge, failed to spot the obvious? Why have they steadfastly refused to acknowledge what should be so easy to see? Even those philosophers, like Byrne and van Inwagen, who grapple with the mysterious nature of modal epistemology, arrive at the final hurdle and, with the finishing line in sight, decide to pull out of the race. Although this collective blind spot is hard to fathom, it brings to mind another, more famous case of a blind spot in epistemology. For aeons, philosophers schooled in a particular tradition accepted the 'JTB' theory of knowledge, until Edmund Gettier detonated this account with a few simple counterexamples. This is despite the fact that Plato, to whom the account was often credited, explicitly argued against it in the Theaetetus! The difference here is that the correct account of modal epistemology is, and continues to be, heavily contested (a state of affairs that, incidentally, was forecast by René Descartes, who considered the pursuit of this kind of modal knowledge a futile endeavour) (Bennett 2000, pp.164-5). I suspect that this contestation will carry on indefinitely, at least until philosophers admit that knowledge of merely metaphysical modality is beyond us. Hopefully my argument here contributes towards realising that (as yet) unrealised possibility.

\section{References}

Armstrong, D. M. 1989. A Combinatorial Theory of Possibility. Cambridge: Cambridge University Press.

Bennett, J. F. 2000. Infallibility and Modal Knowledge in Some Early Modern Philosophers. In: T. Smiley (ed.) Mathematics and Necessity: Essays in the History of Philosophy, pp.13966. Oxford: Oxford University Press.

Bloch, E. 1988. Something's Missing: A Discussion between Ernst Bloch and Theodor Adorno on the Contradictions of Utopian Longing. In: The Utopian Functions of Art and Literature: Selected Essays, pp.1-17. Translated by J. Zipes and F. Mecklenburg. Cambridge, MA: Massachusetts Institute of Technology Press.

Bueno, O.; Shalkowski, S. A. 2014. Modalism and Theoretical Virtues: Toward an Epistemology of Modality. Philosophical Studies 172(3): 671-89.

Byrne, A. 2007. Possibility and Imagination. Philosophical Perspectives 21(1): 125-44.

Chalmers, D. J. 2002. Does conceivability entail possibility? In: T. Gendler; J. Hawthorne (eds.) Conceivability and Possibility, pp.145-200. Oxford: Oxford University Press.

Hartmann, N. 2017 [1938]. The Megarian and the Aristotelian Concept of Possibility: A Contribution to the History of the Ontological Problem of Modality. Translated by Frédéric Tremblay and Keith R. Peterson. Axiomathes 27: 209-23.

Kripke, S. A. 1980. Naming and Necessity. Cambridge, MA: Harvard University Press. 
Leon, F; Fisher, R. W. 2016. The Modal-Knowno Problem. Southwest Philosophy Review 32(1): 225-32.

Lewis, D. K. 1986. On the Plurality of Worlds. Oxford: Blackwell.

Lowe, E. J. 2012. What is the Source of Our Knowledge of Modal Truths? Mind 121(484): 919-50.

Menzel, C. 2016. Possible Worlds. In: E. N. Zalta (ed.) Stanford Encyclopedia of Philosophy. Winter 2016 edition. plato.stanford.edu/archives/win2016/entries/possible-worlds/. Accessed 23 July, 2017.

Nozick, R. 2001. Invariances: The Structure of the Objective World. Cambridge, MA: Harvard University Press.

Smith, Q. 2001. The Metaphysical Necessity of Natural Laws. Philosophica 67(1): 31-55.

Tremblay, F. 2017. Historical Introduction to Nicolai Hartmann's Concept of Possibility. Axiomathes 27: 193-207.

Vaidya, A. The Epistemology of Modality. In: E. N. Zalta (ed.) Stanford Encyclopedia of Philosophy. Summer 2017 edition. plato.stanford.edu/archives/sum2017/entries/modality-epistemology/. Accessed: 28 April, 2017.

van Inwagen, P. 1998. Modal Epistemology. Philosophical Studies 92(1/2): 67-84.

Williamson, T. 2005. The Presidential Address: Armchair Philosophy, Metaphysical Modality and Counterfactual Thinking. Proceedings of the Aristotelian Society 105: 1-23.

- 2007. The Philosophy of Philosophy. Malden, MA: Wiley-Blackwell.

Yablo, S. 1993. Is conceivability a guide to possibility? Philosophy and Phenomenological Research 53(1): 1-42.

\section{Notes}

${ }^{1}$ My usage of the term 'possibility' will follow that of contemporary metaphysicians' usage, which flows all the way down from Aristotle. This term presupposes a conception of possibility, and thus modality, whereby only some of the conditions for an occurrence need to be realised for it to be 'possible'. But this conception has been countered, notably by Diodorus Cronus, a rough contemporary of Aristotle's. Although I only became familiar with his work after this article was sent for publication, Nicolai Hartmann, in a view akin to mine and in line with the Megarian school of thought, argued that such an Aristotelian conception of possibility is merely epistemic and not metaphysical (Tremblay 2017, pp.193-4). As Hartmann (2017[1937]) points out, the Aristotelian notion of possibility assumes a kind of indeterminacy of being - which, I might add, is at odds with many contemporary philosophers' acceptance of nomological determinism - because "the success of the actualization [of what is non-actual] still remains open". However, Hartmann's argument differs from my own he maintains that there is no room for the "ghostly existence" of the 'mere possible' in the real (i.e., actualised) world — and, as this entails necessitarianism, a position that I also seek to rebut, I do not endorse it.

${ }^{2}$ For the rest of this essay, the term 'modality', if not prefaced, will refer to merely metaphysical modality. 
${ }^{3}$ The KK principle is the thesis that if you know $P$, then you also know that you know $P$. But this also means that you know that you know that you know P...ad infinitum. Yet it is not self-evident that this must give rise to an infinite regress, or that such a regress would be vicious, as various internalists will tell you.

${ }^{4}$ Commenting on the tendency of philosophers working in modal epistemology to 'modalise' incessantly, Felipe Leon and Robert Fisher (2016, p.228) write: "We're all operating in a philosophical climate that allows you to dismiss skeptical challenges precisely because they lead to skepticism."

${ }^{5}$ It is not clear how modalising is supposed to work, so I take it this is what is involved in the process.

${ }^{6}$ As I later argue, we can determine what is metaphysically impossible insofar as we can show something to be logically impossible.

${ }^{7}$ Van Inwagen (1998, p.73) also makes this point, but pays no further attention to the problem it poses.

${ }^{8}$ I make no claims here as to what such a moral standard is or should be. I simply make the point that clashing moral intuitions requires that there be an independent basis to morality. My thanks to Prashanti Ramnanan for pressing me to be clear on this point.

${ }^{9} \mathrm{My}$ thanks to an anonymous reviewer for raising this question.

${ }^{10}$ We assume that the light is good and my perception is not faulty, etc.; that is, we avoid pathological scepticism.

${ }^{11}$ This example and substantial portions of the ensuing discussion is taken from Anand Vaidya (2017).

${ }^{12}$ Margot Strohminger (2015) is an example of someone who is guilty of this.

${ }^{13}$ Another way of putting this point is that an intuition cannot decisively tell us whether all the initial conditions that give rise to $\mathrm{P}$ can bring about the actuality of $S$ being in $L^{*}$ (instead of $L$ ).

${ }^{14}$ Other uncontroversial types of sensuous imagination, according to Byrne (2007, p.134), are auditory and kinaesthetic imagination.

${ }^{15}$ As Ruth Marcus first quantified.

${ }^{16}$ Byrne is as noncommittal as van Inwagen and maintains, despite his arguments, that there must be some things which we can know to be possible, making this 'knowledge' more mysterious than ever.

${ }^{17}$ One would be hard-pressed to deny that we can conceive of ghosts (and other similar incorporeal, immaterial agents) when there are so many people who believe in their existence.

${ }^{18}$ Adapted from Vaidya (2017).

${ }^{19} \mathrm{An}$ anonymous reviewer has pointed out that "not all absolute impossibilities are narrowly logical". That is true. It is with this in mind that I indicated in my taxonomy of modality that my use of the term 'logical impossibility' will make room for analytical impossibilities, which includes semantic impossibilities, too. This is to allow for cases, such as 'married bachelor/ette', which need some kind of non-logical axioms operating as meaning postulates (or something similar) to entail a contradiction, in the schema. My thanks to the reviewer for pushing me to be clear on this point.

${ }^{20}$ This was written before Eliud Kipchoge ran the distance of a marathon in under two hours on 12 October, 2019. This was a special event not open to other athletes, with standard rules for pacing and fluids not followed, and so it does not count as an official new marathon 
record. Thus, as it stands at the time of writing, it is still logically possible that someone will never break the two-hour mark for running in an official marathon.

${ }^{21}$ It does not matter for my purposes here whether it is claimed that possible worlds exist concretely — David Lewis (1986) being the most ardent proponent of hardcore modal realism - or whether they exist only as abstract entities — what Lewis calls 'ersatzism'. Either way, our only way of epistemically accessing possible worlds would be through our imaginative faculties. Fictionalist accounts of possible worlds, whereby possible worlds are to be treated in an analogous manner to fictions, such that talk of possible worlds is, strictly speaking, false, but nevertheless able to yield 'truths', will not suffice either. The problem is that the very concept of hypothetical counterfactuals cannot grant merely metaphysical modal knowledge.

${ }^{22}$ In light of this, we could treat the semantics of 'possible worlds' according to Saul Kripke's (1980, p.15) suggestion and speak of 'counterfactual situations' instead. But this will not help us in our quest for modal knowledge. From van Inwagen's (1998, p.75) simple observation that in the attempt to determine whether or not $P$ is in fact possible (i.e., whether or not it could have happened), we know that the construction of a counterfactual scenario involving $P$ "will be of no use if [the scenario itself] is impossible". Significantly, the latter is something which we have no way of knowing (unless it is logically impossible), so the grounds for justifying modal claims have simply been pushed back one step.

${ }^{23}$ There are difficult, unresolved questions about what the extent of our knowledge in this arena is or can be. While the extent of our knowledge here may be legitimately disputed, I do not doubt that we can have at least some knowledge via counterfactual conditionals. I elaborate on this point in Section V.

${ }^{24}$ Again, this is on the Aristotelian conception of possibility that I employ throughout this essay.

\section{Acknowledgments}

I would like to thank Monique Whitaker for inviting me to present an earlier version of this essay at the conference on Contemporary Language, Logic and Metaphysics: African and Western Approaches, held at the University of Witwatersrand from 14 to 16 August, 2017, as well as for her insightful comments on an early draft. My thanks also goes to the audience members at my talk, many of whom asked instructive questions. I appreciate the anonymous reviewer mentioned in the article for their valuable feedback. Finally, I would like to express my gratitude to Prashanti Ramnanan for her critical observations and encouragement throughout the writing process. I take sole responsibility for any errors that remain. 